\title{
O Compliance Criminal como instrumento de garantia dos Direitos Humanos dos trabalhadores de organizações Empresariais
}

\section{Criminal Compliance as a Human Rights guarantee instrument for business organizations' employees}

\author{
Fábio Roque da Silva Araújo ${ }^{1}$ \\ Luíza Moura Costa Spínola ${ }^{2}$ \\ Raquel El-Bachá Figueiredo ${ }^{3}$
}

\begin{abstract}
RESUMO:
O presente trabalho tem por escopo analisar como os programas de cumprimento normativo podem proteger os direitos humanos dos trabalhadores, sobretudo no que tange aos crimes trabalhistas. A justificativa para a construção desse artigo é compreender melhor essa tendência no meio empresarial. Há uma movimentação no cenário internacional voltada para uma política penal de prevenção a esse tipo de criminalidade, na qual Estados e organizações pressionam as empresas a atuarem em conformidade com a legislação sobre o assunto. Tais crimes trabalhistas devem ser evitados por meio de medidas voltadas ao combate às violações aos direitos dos trabalhadores. Para elucidar essa questão relativa ao compliance e à efetivação dos Direitos Humanos será utilizada a metodologia de revisão bibliográfica. Por meio da análise dessa questão metodológica, considera-se que as medidas de compliance criminal podem ser efetivas tanto para promover a responsabilidade social da empresa quanto para tutelar os direitos humanos, promovendo um cenário empresarial mais íntegro.
\end{abstract}

\section{PALAVRAS-CHAVE:}

Compliance Criminal; Direitos Humanos; Responsabilidade Social da Empresa.

\section{ABSTRACT:}

This paper aims to analyze how compliance programs can protect workers' human rights, especially with regard to labor crimes. The justification of this article is to comprehend this

\footnotetext{
${ }^{1}$ Doutor em Direito Público pela Universidade Federal da Bahia (2015). Atualmente é Professor Assistente da Universidade Federal da Bahia e Juiz Federal na Bahia. Tem experiência na área de Direito, com ênfase em Direito Penal, atuando principalmente nos seguintes temas: Segurança Pública, Sistema Prisional e Direito Penal Garantidor.

${ }^{2}$ Advogada formada pela Faculdade de Direito da Universidade Federal da Bahia. Especialista em Ciências Criminais pela Faculdade Baiana de Direito. Especializada em Crime Organizado, Corrupção e Terrorismo pela Universidade de Salamanca. Concluiu o Curso Internacional IBCCRIM Coimbra de Direito Penal Econômico. Tem interesse em Direito Penal, Processo Penal, Direito Penal Econômico e Direito Internacional. Mestranda em Direito na Universidade Católica do Salvador.

${ }^{3}$ Possui graduação em Direito pela Universidade Salvador (2007) e especialização em Direito Público pela Universidade Salvador (2009). É defensora pública na Defensoria Pública do Estado do Amazonas. Mestranda em Direito pela Universidade Católica do Salvador. Tem experiência na área de Direito, com ênfase em Direito Penal e Direito Processual Penal.
} 
trend in the business environment. There is a movement on the international scene towards a criminal policy to prevent this type of crime, in which states and organizations pressure companies to act in accordance with the legislation on the subject. Such labor crimes should be prevented by measures aimed at combating violations of workers' rights. Bibliographic review methodology will be used in order to clarify this issue regarding compliance and the effectiveness of Human Rights. Considering the analysis of this methodological issue, it is concluded that criminal compliance measures can be effective to promote corporate social responsibility and to protect human rights, promoting a healthier business environment.

\section{KEYWORDS:}

Criminal Compliance; Human Rights; Corporate Social Responsibility.

\section{INTRODUÇÃO}

Sabe-se que há uma preocupação recorrente das empresas com a chamada responsabilidade social corporativa. Não se admite mais a ideia de que a empresa é uma organização voltada apenas para o lucro: ela precisa desempenhar suas atividades em consonância com as normas que protejam os direitos humanos.

Ainda é possível afirmar que, atualmente, há uma tendência mundial no sentido de pressionar as corporações a assegurarem os direitos fundamentais dos seus empregados. Tais direitos devem ser respeitados de maneira que as atividades desempenhadas por eles no âmbito da empresa não sejam consideradas práticas abusivas. Há muito se admite que tais direitos apresentam um efeito irradiador que deve permear não apenas as relações Estado-cidadão, mas também a relação entre particulares.

Para assegurar que a organização se comprometa com medidas éticas, que estejam em conformidade com a legislação nacional e estrangeira que versa sobre direitos humanos, são necessárias medidas de compliance, também chamadas de medidas de cumprimento normativo. A adoção de um programa de compliance apresenta vários benefícios para a empresa.

Nesse trabalho será tratado o ramo do compliance denominado compliance criminal ou penal, que visa reduzir os riscos da ocorrência de crimes no desempenho das atividades da empresa. Será feita uma breve explanação desse conceito e de como ele pode ser aplicado à 
prevenção de crimes trabalhistas de redução à condição de análoga de escravo e tráfico humano. Para explanar esses e os demais conceitos mencionados nesse artigo será empregado o método de revisão de bibliografia.

Um crime trabalhista é, antes de tudo, uma violação a um bem jurídico do trabalhador, um desrespeito aos seus direitos fundamentais. Crimes como redução à condição análoga de escravo e tráfico humano causam diversos prejuízos para as vítimas não somente de ordem material, mas também de saúde e emocional. Assim, esses crimes serão brevemente analisados para explicar seus elementos e com que frequência os mesmos ocorrem em relações trabalhistas ilegais.

Sabe-se ainda que organizações internacionais que vinculam países da América e Europa vêm manifestando cada vez mais interesse nessa causa. Os direitos fundamentais de qualquer indivíduo devem ser levados em consideração nas relações empregatícias, o que demonstra o reconhecimento da dignidade da pessoa humana como um valor da sociedade ocidental.

Por fim, serão explanadas vantagens da adoção de um programa de conformidade normativa que leve em consideração as normas internas e internacionais sobre direitos humanos. Alguns mecanismos que podem compor tal modelo de negócio serão mencionados, bem como casos de empresas que tiveram prejuízos devido à não observância das normas de direitos humanos em suas relações trabalhistas.

\section{DESENVOLVIMENTO DO INSTITUTO E O COMPLIANCE CRIMINAL}

O termo compliance provém do verbo em inglês "to comply", que significa agir em conformidade com algo. No meio empresarial, a palavra significa a conformidade da empresa 
em relação às leis, diretrizes e regulamentos internos e externos. A observância dessas normas tem como finalidade diminuir risco relativo à reputação e o risco regulatório ${ }^{4}$.

São consideradas ferramentas do programa de compliance as medidas por meio das quais as empresas pretendem assegurar de que sejam observadas as normas vigentes para elas e seus funcionários, de forma que a tarefa de identificar irregularidades se torne mais fácil, de acordo com Kuhlen ${ }^{5}$. Nessa hipótese, as devidas providências são adotadas para fazer cessar a situação em desconformidade com a legislação, bem como medidas para mitigar os prejuízos causados.

Um programa de compliance apresenta como uma de suas finalidades a preservação da responsabilidade civil e criminal dos proprietários, gerentes e conselheiros da organização, pois pode vir a minorar e prevenir erros na administração da empresa. Cabe ressaltar, contudo, que o conceito de compliance não é tão atual a nível internacional quanto é no Brasil, conforme elucida Sá6.

Para Nieto Martín", é possível utilizar a expressão "cumprimento normativo" como sinônimo de compliance, sendo esse um termo que significa atuar conforme a legalidade. Sobre o termo "legalidade", o autor espanhol esclarece que esse deve ser compreendido em sentido amplo, o que inclui o cumprimento de obrigações decorrentes da legislação (administrativa, civil, penal e trabalhista), por exemplo, bem como orientações da empresa contidas em normas internas e em seu código de conduta.

Um programa voltado à conformidade normativa deve buscar minimizar os riscos de acordo com a complexidade de seus negócios e propagar a cultura de controle para garantir o cumprimento das leis e regulamentos existentes. Os custos de não estar em conformidade para

\footnotetext{
${ }^{4}$ COIMBRA, Marcelo de Aguiar; MANZI, Vanessa Alessi. Manual de compliance: preservando a boa governança e a integridade das organizações. São Paulo: Atlas, 2010, p. 2.

5 KUHLEN, Lothar. Cuestiones Fundamentales de Compliance y Derecho Penal. In: KUHLEN, Lothar; MONTIEL, Juan Pablo; GIMENO, Ínigo Ortiz de Urbina. Compliance y Teoría del Derecho Penal. Madrid: Marcial Pons, 2013, p. 51.

${ }^{6}$ SÁ, Ana Luíza. Compliance Criminal: reflexos de sua adoção pelo particular. In: SAAD-DINIZ, Eduardo; ADACHI, Pedro Podboi; DOMINGUES, Juliana Oliveira (Org.). Tendências em governança corporativa e compliance. São Paulo: LiberArs, 2016. p. 223.

${ }^{7}$ NIETO MARTÍN, Adán. O Cumprimento Normativo. In: NIETO MARTÍN, Adán; LASCURAÍN SÁNCHEZ, Juan Antonio; GARCÍA DE LA GALANA, Beatriz; FERNANDEZ PÉREZ, Patricia; BLANCO CORDERO, Isidoro. Manual de Cumprimento Normativo e Responsabilidade Penal das Pessoas Jurídicas. Florianópolis: Tirant ló blanch, 2018, p. 29.
} 
uma empresa podem ser bastante elevados e incluem danos à reputação da organização e, por conseguinte, à reputação do seu corpo de colaboradores, bem como a perda de valor da marca. Podem acarretar sanções administrativas e, de acordo com a situação, até mesmo, criminais às organizações e aos indivíduos ${ }^{8}$.

Dentre as vantagens da adoção de um programa de conformidade normativa está a redução considerável do risco de violação a determinados bens jurídicos tutelados pelo direito penal. Brito ${ }^{9}$ explica que o compliance apresenta alguns aspectos que contribuem para esse objetivo, tais como a análise dos riscos de cometimento de crimes, específicos à atividade da organização, o estabelecimento de uma cultura de cumprimento de normas concernentes à empresa e, por conseguinte, a imposição de deveres de comunicação e de transparência entre seus funcionários.

Nesse trabalho se utilizará o conceito de criminal compliance, também chamado de compliance penal ou criminal. Esse termo se refere ao programa de conformidade normativa que possui como objetivo a prevenção da ocorrência de crimes. De acordo com Saavedra ${ }^{10}$, esse novo campo de pesquisa das Ciências Criminais é visto pelos acadêmicos como o estudo dos controles internos e de demais medidas que podem ser adotadas em empresas e instituições financeiras com o objetivo de precaver atividades delituosas.

Segundo Benedetti ${ }^{11}$, um programa de conformidade normativa voltado às normas penais não está limitado à prevenção de crimes no âmbito da empresa, mas também visa prevenir a possível responsabilidade penal de seus dirigentes. Assim, o compliance criminal possibilita que se desenvolva uma cultura ética nas relações de trabalho entre as pessoas que trabalham na empresa, desde os executivos responsáveis pela gestão das ações empresariais até os funcionários de baixo escalão. Ademais, um programa de compliance pode ser aplicado em

\footnotetext{
${ }^{8}$ COIMBRA, Marcelo de Aguiar; MANZI, Vanessa Alessi, op. cit., p. 4.

9 BRITO, Teresa Quintela de. Relevância dos mecanismos de "Compliance" na responsabilização penal das pessoas coletivas e dos seus dirigentes. Revista de Ciências Jurídico-Criminais, Coimbra: 2014, p. 80.

${ }^{10}$ SAAVEDRA, Giovani Agostini. Reflexões iniciais sobre criminal compliance. Boletim IBCCRIM, São Paulo, ano 18, n. 218, p. 11-12, jan. 2011. Disponível em: http://espacocriminologico.blogspot.com.br/2011/01/reflexoesiniciais-sobre-criminal.html. Acesso em: 22 de jun. 2019.

${ }^{11}$ BENEDETTI, Carla Rahal. Criminal Compliance: instrumento de prevenção criminal corporativa e transferência de responsabilidade penal. São Paulo: Quartier Latin, 2014, p. 86.
} 
todas as relações sociais na organização, pois a adesão às normas de integridade em uma determinada empresa resulta em um produto constituído de boas práticas.

Pode-se considerar que uma boa imagem perante a sociedade é uma das características mais relevantes e mais difíceis de uma empresa manter em longo prazo. A reputação de uma organização como ética se trata de um fator que torna a empresa mais atraente para investidores e para o público consumidor de seus produtos ou serviços. Isso acontece em virtude do caráter intangível de alguns componentes do valor de uma empresa - tais como o capital intelectual, a imagem e a marca - que são responsáveis de maneira direta pelos seus rendimentos financeiros ${ }^{12}$.

Entretanto, a função do compliance penal transcende o fato de ser um mecanismo de administração com a finalidade de promover práticas de integridade e em conformidade com a legislação no âmbito de uma empresa. Trata-se de um instrumento de prevenção que tem como objetivo evitar a responsabilização criminal dos gestores das organizações empresariais. Para Cabette e Nahur ${ }^{13}$, a criação de um programa de conformidade normativa tem origem no receio quanto à ocorrência de crimes e as respectivas consequências para a empresa e seus administradores e funcionários.

O compliance criminal se trata de uma tendência internacional seguida pelos modelos empresariais da atualidade para fins de prevenção aos ilícitos cometidos no meio corporativo. Essa inclinação pode ser considerada como uma reação aos escândalos de corrupção e de fraude e como exigência para a prevenção de crises financeiras de alcance mundial. Assim, os estudiosos do direito penal econômico têm voltado seus debates em torno do estabelecimento de novos padrões de imputação e de uma nova orientação inclinada à colaboração preventiva entre os indivíduos, as empresas e o Estado. Quanto ao modelo adotado no Brasil para a prevenção à criminalidade empresarial, ainda não se pode considerar que há um alinhamento em relação a determinados padrões de gestão e condução da atividade empresarial ${ }^{14}$.

\footnotetext{
${ }^{12}$ CARDOSO, Débora Motta. Criminal compliance na perspectiva da lei de lavagem de dinheiro. São Paulo: LiberArs, 2015, p. 67-68.

13 CABETTE, Eduardo Luiz Santos; NAHUR, Marcius Tadeu Maciel. Criminal Compliance e Ética Empresarial. Porto Alegre: Núria Fabris, 2013, p. 17.

${ }^{14}$ SAAD-DINIZ, Eduardo. Novos modelos de responsabilidade empresarial: a agenda do direito penal corporativo. In: SAAD-DINIZ Eduardo; ADACHI, Pedro Podboi; DOMINGUES, Juliana Oliveira (Org.). Tendências em governança corporativa e compliance. São Paulo: LiberArs, 2016. p. 95.
} 
Um programa de conformidade normativa pode influenciar tanto no manejo dogmático quanto na percepção do dolo, da violação do dever de cuidado e em outros marcos normativos regulatórios, como na determinação da pena e dos deveres do garantidor, baseados na prevenção de determinados resultados. Trata-se de uma perspectiva atual no campo do direito penal econômico: um novo paradigma com o pendor do ordenamento jurídico à responsabilidade penal empresarial ou com formas de responsabilização indireta, com lastro no direito administrativo sancionador ${ }^{15}$.

Faz-se relevante ressaltar que o programa de cumprimento normativo voltado à prevenção de crimes é um instrumento de controle corporativo interno e externo e atua de forma ex ante, conforme destaca Benedetti ${ }^{16}$, o que significa que atua de forma preventiva, com a elaboração de uma análise jurídica de todas as ações concernentes à atividade da empresa, tanto em relação aos colaboradores que atuam internamente, quanto em relação ao cliente do objeto ofertado.

De acordo com Sarcedo ${ }^{17}$, são objetivos comuns tanto da governança corporativa quanto do compliance penal o estabelecimento e a adoção de políticas não apenas de prevenção, mas também para solucionar e reparar situações e problemas que não puderam ser contidos pelos mencionados mecanismos de controle. $\mathrm{O}$ autor ainda elucida que essas políticas, da perspectiva jurídico-penal, devem ser consideradas para que se possa delimitar a culpabilidade corporativa, não obstante essa categoria dogmática não esteja sendo observada devidamente por boa parte das legislações dos países que admitem o modelo da responsabilidade penal da pessoa jurídica.

Os mecanismos de compliance criminal podem ser considerados não apenas no que tange à sua aplicação para prevenir crimes, mas em todas as áreas que podem acarretar riscos à empresa, sendo manifestações de autorregulação, uma vez que são procedimentos de controle e fiscalização para que a organização atue em conformidade com as leis e regulamentos concernentes à sua atividade.

\footnotetext{
15 Ibidem, p. 97.

16 BENEDETTI, Carla Rahal, Idem, 2014, p. 81.

${ }^{17}$ SARCEDO, Leandro. Compliance e responsabilidade penal da pessoa jurídica: construção de um novo modelo de imputação baseado na culpabilidade corporativa. São Paulo: Saraiva, 2016, p. 45.
} 
Parece correto o posicionamento de Silveira e Saad Diniz ${ }^{18}$ no sentido que a autorregulação regulada, considerada um dos sustentáculos do criminal compliance, apresenta como principal escopo a prevenção de atos delitivos, como a corrupção, a lavagem de dinheiro, o financiamento ao terrorismo, crimes contra a livre concorrência, crimes contábeis e tributários e crimes ambientais.

Ressalte-se que, além dos crimes mencionados, um conjunto de medidas de conformidade normativa pode ser empregado para prevenir a ocorrência de crimes contra a organização do trabalho, tais como a escravidão e o tráfico de pessoas, condutas que ainda são comuns em diversos países. Essa é uma questão que ainda desafia autoridades e, para sua erradicação, é demandada a participação das empresas. Nesse trabalho, explicar-se-á o conceito de trabalho escravo em uma seção posterior.

Um programa de compliance nesse sentido seria um mecanismo para evitar a ocorrência de crimes trabalhistas. Dessa forma, trata-se de uma medida a ser adotada pela empresa que pode levar à diminuição de despesas com questões judiciárias, de riscos reputacionais e da prevenção da responsabilidade de executivos da organização.

O trabalho escravo, crime trabalhista que ainda ocorre com bastante frequência, é evidentemente uma das formas mais brutais de violação à dignidade da pessoa humana. Se o sentido clássico dos direitos fundamentais se volta para ações positivas e negativas por parte do Estado em relação ao cidadão, nesse caso há direitos fundamentais que podem vir a ser descumpridos por um ente particular, no caso, a empresa. Há muito a doutrina menciona o caráter irradiador dos direitos fundamentais, de modo que todo o ordenamento jurídico deve ser interpretado em conformidade com eles, o que inclui a legislação concernente a pessoas jurídicas.

Considera-se que há, inclusive, um esforço dos atores do cenário internacional nesse sentido. Terradillos Basoco ${ }^{19}$ menciona que, em 2010, a Fédération Internationale de Football Association (FIFA) designou como sede da Copa de 2022 o Catar. Contudo, organizações

\footnotetext{
${ }^{18}$ SILVEIRA, Renato de Mello Jorge; SAAD-DINIZ, Eduardo. Compliance, Direito Penal e Lei Anticorrupção. São Paulo: Saraiva, 2015, p. 118.

${ }^{19}$ BASOCO, Juan María Terradillos. Explotación laboral, trabajo forzoso, esclavitud. In: CRESPO, Eduardo Demetrio; NIETO MARTÍN, Adán. Derecho penal econômico y Derechos Humanos, Valencia: 2018, p. 215216.
} 
internacionais como a Humans Right Watch e a Organização Mundial do Trabalho (OIT) denunciaram o país por conta das más condições laborais de quase dois milhões de operários responsáveis pela construção de hotéis e instalações esportivas. O Catar ficou encarregado de solucionar essa situação, caso contrário não sediaria o campeonato mundial de futebol. $\mathrm{O}$ autor menciona que deve haver uma política penal preventiva para promover condições laborais dignas, ou seja, Estados e países devem se preocupar com questões de compliance criminal trabalhista.

Nesse trabalho será empregado o conceito de cumprimento normativo não somente para evitar uma responsabilização criminal do empresário, mas para promover um cenário empresarial mais sadio por meio da observância dos direitos fundamentais dos trabalhadores de organizações empresariais.

\section{A PROTEÇÃO AOS DIREITOS HUMANOS E SUA REPERCUSSÃO ENTRE PESSOAS FÍSICAS E JURÍDICAS}

De acordo com Dimoulis e Martins ${ }^{20}$, direitos fundamentais são direitos públicosubjetivos, cujos titulares podem ser pessoas físicas ou jurídicas, que estão previstos em dispositivos constitucionais. Assim, esses direitos apresentam caráter normativo supremo no âmbito do Estado e têm como objetivo limitar a atuação estatal relativa à liberdade da pessoa. Posteriormente, tais direitos passaram a ser compreendidos como direitos a prestação em sentido estrito em face do Estado. Tratam-se dos direitos fundamentais sociais, como o direito à saúde, ao trabalho, à moradia e à educação, como leciona Alexy ${ }^{21}$.

Faz-se relevante explicar a distinção entre as expressões "direitos fundamentais" e “direitos humanos", Para Sarlet ${ }^{22}$, direitos fundamentais são sempre direitos humanos, pois os seres humanos são titulares desses direitos, mesmo que representados por entidades coletivas.

\footnotetext{
${ }^{20}$ DIMOULIS, Dimitri.; MARTINS, Leonardo. Teoria Geral dos Direitos Fundamentais: 3. ed. São Paulo: Editora Revista dos Tribunais, 2011, p. 49.

${ }^{21}$ ALEXY, R. Teoria dos Direitos Fundamentais: 2. ed. São Paulo: Malheiros Editores, 2011, p. 499.

${ }^{22}$ SARLET, Ingo Wolfgang. A Eficácia dos Direitos Fundamentais: uma teoria geral dos Direitos Fundamentais na perspectiva constitucional: 11. ed. Porto Alegre: Livraria do Advogado Editora, 2012, p. 29.
} 
O termo "direitos fundamentais" se aplica aos direitos do ser humano reconhecidos e previstos pelo direito constitucional positivo de um Estado. Já a expressão “direitos humanos” relacionase ao conteúdo dos documentos de direito internacional e indica posicionamentos jurídicos relativos aos direitos dos indivíduos, sem dependência de sua relação com certa ordem constitucional.

A ideia de direitos inerentes aos cidadãos, como dignidade, liberdade, já era mencionada desde antes do Renascimento, mas essas noções não eram concebidas como direitos, conforme esclarece $\mathrm{Amaral}^{23}$. O autor explica que as três formas históricas iniciais dos direitos fundamentais consistem, essencialmente, nos limites do poder, no debate acerca da questão da tolerância e nas garantias do indivíduo no âmbito do processo penal. Essas formas foram previstas nas primeiras declarações de direito das revoluções liberais e equivalem às liberdades individuais, aos direitos políticos e de participação e às garantias processuais.

Os direitos fundamentais foram manifestados inicialmente para afirmar a liberdade da fé e, posteriormente, para se opor aos fundamentos do poder absoluto e para proporcionar a humanização do direito penal e do processo penal ${ }^{24}$. Após a vitória das chamadas revoluções liberais em países como a França e os Estados Unidos, os direitos fundamentais passaram a ser reconhecidos em textos constitucionais tanto desses quanto de outros países.

Considera-se como noção basilar dos direitos fundamentais a dignidade da pessoa humana. Sarmento ${ }^{25}$ elucida que tal noção é considerada a origem dos direitos não enumerados, mas não se trata de um direito fundamental propriamente dito. Para o autor, a dignidade tem por objetivo garantir uma proteção integral ao ser humano e não salvaguardar somente elementos pontuais inerentes à sua condição de indivíduo.

Um dos aspectos da dignidade da pessoa humana é o valor intrínseco do indivíduo, que não permite sua instrumentalização para que terceiros tirem proveito ou com o objetivo de alcançar metas coletivas, conforme ensinamentos de Sarmento ${ }^{26}$. A igualdade, elemento que

\footnotetext{
${ }^{23}$ AMARAL, Gustavo. Direito, Escassez \& Escolha: Em busca de critérios jurídicos para lidar com a escassez de recursos e as decisões trágicas. Rio de Janeiro: Renovar, 2001, p. 50.

${ }^{24}$ Idem.

${ }^{25}$ SARMENTO, Daniel. Dignidade da Pessoa Humana: conteúdo, trajetórias e metodologia. Belo Horizonte: Editora Fórum, 2016, p. 88-89.

${ }^{26}$ Ibidem, p. 92.
} 
exclui categorias de cunho social ou cultural para titularidade dos direitos fundamentais, seria outro componente da dignidade.

É possível também citar como aspecto da dignidade humana o chamado mínimo existencial, que envolve a proteção de condições inerentes a uma existência considerada digna. Ademais, a questão do reconhecimento, ligado ao respeito à identidade do indivíduo, tanto no âmbito individual quanto coletivo, nas instituições, bem como nas relações intersubjetivas, pode ser entendida como um elemento inerente à dignidade da pessoa humana.

Sarmento $^{27}$ explica que, no ordenamento jurídico brasileiro, a dignidade da pessoa humana apresenta diversas funções, sendo que algumas seriam dotadas de maior importância como, por exemplo: a atuação da dignidade como fator legitimante do Estado e do Direito; orientação para a hermenêutica jurídica; padrão para o controle de atos do Estado e de particulares; causa limitante de direitos fundamentais; e orientação, na hipótese de ponderação de interesses colidentes.

$\mathrm{Na}$ atual conjuntura social e econômica, nota-se uma crescente capacidade de influência de alguns atores privados que, muitas vezes, possuem um poder econômico superior ao de muitos países. Nesse contexto, torna-se imprescindível reconhecer que os direitos fundamentais devem ser observados nas relações entre particulares, especialmente nos casos em que uma das partes é hipossuficiente em relação à outra. Trata-se de um fenômeno conhecido como constitucionalização do direito privado. O emprego desse termo, conforme explica Sarmento ${ }^{28}$, significa um processo que ocasiona mudanças substantivas relevantes nas formas de compreender as instituições desse ramo do direito.

Segundo Alexy ${ }^{29}$, na jurisprudência do Tribunal Constitucional alemão são encontradas decisões favoráveis ao chamado "efeito irradiador" das normas de direitos fundamentais no sistema jurídico com o respaldo da noção de ordem objetiva de valores. Não se pode afirmar que os direitos fundamentais não se relacionam com relações entre particulares, porque isso não está em conformidade com a diretriz básica segundo a qual os direitos fundamentais seriam

\footnotetext{
${ }^{27}$ Ibidem, p. 77.

${ }^{28}$ SARMENTO, Daniel. Direitos Fundamentais e Relações Privadas. Rio de Janeiro: Lumen Juris, 2006, p. 8384.

${ }^{29}$ ALEXY, Robert., op. cit., p. 525.
} 
direitos relativos a todos os seres humanos. Assim, o autor conclui que as normas de direitos fundamentais possuem caráter objetivo, pois produzem efeitos em relação à coletividade em geral, e não somente em relações Estado-indivíduo. Relações trabalhistas entre uma pessoa física e uma pessoa jurídica, portanto, também devem respeitar tais normas.

Constata-se que há uma preocupação antiga por parte dos Estados e das Organizações Internacionais no que tange à salvaguarda dos direitos humanos. Mazzuoli e Cunha ${ }^{30}$ esclarecem que a proteção dos direitos humanos se relaciona ao sistema jurídico de direito internacional público e que o sistema jurídico interno de cada Estado fica incumbido de tutelar os direitos fundamentais.

Os autores ainda explicam que a tutela dos direitos humanos a nível internacional tem como respaldo os chamados sistemas de proteção ${ }^{31}$. Existem dois modelos de proteção para tais direitos: o sistema global e o sistema regional, presente nos continentes africano, americano e europeu. Esses sistemas estão sempre em contato com o objetivo de proteger os indivíduos sujeitos de direito. Ademais, esses sistemas são coadjuvantes e complementares em relação aos sistemas internos de defesa dos direitos humanos. Em outras palavras, é encargo do Estado, inicialmente, promover e salvaguardar os direitos humanos dos indivíduos que estão em seus respectivos territórios, de modo que o direito internacional de proteção de tais direitos só deve atuar posteriormente, caso não haja no plano interno a tutela devida ou a tutela proporcionada pelos Estados seja falha.

Mazzuoli e Cunha ${ }^{32}$ consideram que há uma atuação global cada vez mais intensa voltada para promover e assegurar o cumprimento dos direitos estabelecidos na Declaração Universal dos Direitos Humanos. Esse movimento apresenta impactos diretos no que tange ao enfrentamento de violações aos direitos humanos, pois estabelece uma rede de normas que os Estados são pressionados a cumprir, o que dificulta violações aos direitos humanos, principalmente quando o direito interno promove o combate às referidas práticas.

\footnotetext{
30 MAZZUOLI, Valério; CUNHA, Matheus Lourenço Rodrigues da. Compliance: de instrumento de sustentabilidade empresarial a mitigador de violações a direitos humanos e fundamentais. Revista Jurídica UNIGRAN. Dourados, v. 20, n. 39, p. 24.

${ }^{31}$ Idem

${ }^{32}$ Ibidem, p. 25.
} 
Cumpre salientar que a Constituição de 1988 trata a prevalência dos direitos humanos como princípio fundamental que rege o Estado nas suas relações internacionais. ${ }^{33} \mathrm{~A}$ consagração deste princípio pelo texto constitucional implica a abertura da ordem jurídica interna ao sistema internacional de proteção aos direitos humanos, na medida em que demanda um maior engajamento do Brasil no processo de elaboração de normas atreladas à este sistema. $^{34}$

Ressalte-se, ainda, que, após dispor expressamente sobre diversos direitos e garantias fundamentais nos incisos do art. $5^{\circ}$, a Constituição Federal estabelece no $\S 2^{\circ}$ do mesmo artigo que tais direitos e garantias expressos não excluem outros decorrentes de tratados internacionais dos quais o País seja signatário.

Quanto à posição hierárquica dos tratados internacionais de direitos humanos, $\operatorname{Ramos}^{35}$ esclarece que houve intenso debate doutrinário até a edição da Emenda Constitucional $\mathrm{n}^{\mathrm{o}} 45 / 2004$. O autor afirma que o citado debate se resume a quatro posicionamentos quanto à natureza dos tratados de direitos humanos: supraconstitucional, em razão de sua origem internacional; constitucional; equiparada à lei ordinária; supralegal.

A Emenda Constitucional $\mathrm{n}^{\circ} 45 / 2004$ acrescentou o $\S 3^{\circ}$ ao art. $5^{\circ}$ condicionando a hierarquia constitucional à observância do rito necessário à aprovação das emendas constitucionais, qual seja, a aprovação pelo quórum de três quintos dos respectivos membros de cada Casa do Congresso Nacional em dois turnos. A referida emenda, além de tornar mais difícil o alcance desse status constitucional pelos tratados de direitos humanos, não fez menção aos tratados ratificados antes da sua edição. ${ }^{36}$

Piovesan ${ }^{37}$ entende que, em decorrência do disposto no $\S 2^{\circ}$ do art. $5^{\circ}$ da Constituição de 1988, todos os tratados de direitos humanos compõem um bloco de constitucionalidade, sendo materialmente constitucionais, independente do quórum de sua aprovação. Neste sentido, a autora afirma que o quórum exigido pelo $\S 3^{\circ}$ do art. $5^{\circ}$ apenas impossibilitaria a denúncia dos

\footnotetext{
${ }^{33}$ BRASIL. Constituição da República Federativa do Brasil. Disponível em: www.planalto.gov.br/cf1988.

${ }^{34}$ PIOVESAN, Flávia. Direitos humanos e o direito constitucional internacional. 11 ed. rev. e atual. São Paulo: Saraiva, 2010, p.40.

${ }^{35}$ RAMOS, André de Carvalho. Teoria geral dos direitos humanos na ordem internacional. 2 ed. São Paulo: Saraiva, 2012, p.146.

${ }^{36}$ Ibidem, p. 146-147.

${ }^{37}$ PIOVESAN, Flávia. op. cit. , p.72.
} 
tratados de direitos humanos, tendo em vista que sua observância os tornaria formalmente constitucionais.

Divergindo de Piovesan quanto à impossibilidade de denúncia dos referidos tratados, $\operatorname{Ramos}^{38}$ sustenta que as denúncias devem ser analisadas pelo Congresso Nacional, uma vez que os tratados de direitos humanos estão relacionados à dignidade humana, devendo, entretanto, ser observado quórum diferenciado de acordo com o rito adotado para a aprovação do tratado.

Ainda quanto à natureza dos tratados de direitos humanos, a partir do julgamento do RE 466.343-SP ${ }^{39}$, o Supremo Tribunal Federal passou a adotar a tese, que prevalece atualmente, de que os tratados internacionais que versam sobre direitos humanos, anteriores ou posteriores à edição da Emenda Constitucional no $45 / 2004$, que não observem o rito disposto no $\S 3^{\circ}$ do art. $5^{\circ}$ do texto constitucional têm status supralegal.

Ultrapassada a compreensão do status dos tratados internacionais de direitos humanos, faz-se necessário apontar quais são os mecanismos de monitoramento e proteção dos direitos humanos no âmbito da Organização das Nações Unidas (ONU). São mecanismos convencionais os comitês voltados à implementação de cada uma das convenções de direitos humanos do sistema universal, à exemplo do Comitê sobre Direitos Econômicos, Sociais e Culturais.

Em virtude da ineficiência dos mecanismos fundados nas convenções para compelir os Estados a cumprir as obrigações assumidas, a Comissão de Direitos Humanos da ONU, adotou novos mecanismos, conhecidos como mecanismos não-convencionais, previstos diretamente na Carta das Nações Unidas. ${ }^{40} \mathrm{O}$ Conselho de Direitos Humanos é um mecanismo nãoconvencional, criado em substituição à Comissão de Direitos Humanos, podendo receber

\footnotetext{
${ }^{38}$ RAMOS, André de Carvalho. Teoria geral dos direitos humanos na ordem internacional. 2 ed. São Paulo: Saraiva, 2012, p.149.

${ }^{39}$ BRASIL. Supremo Tribunal Federal. Recurso Extraordinário n.466.343-SP. Recorrente: Banco Bradesco S.A. Recorrido: Luciano Cardoso Santos. Relator: Min.Cezar Peluso. DJe 104. Publicado em 05.06.2009. Disponível em: http://redir.stf.jus.br/paginadorpub/paginador.jsp?docTP=AC\&docID=595444.

${ }^{40}$ WEISS, Carlos. Direitos humanos contemporâneos. 2 ed. 3 tiragem. São Paulo: Malheiros Editores, 2012, p.120.
} 
reclamações quando houver indícios consistentes da existência de graves violações aos direitos humanos, como aqueles direitos humanos decorrentes da relação de trabalho.

O Conselho de Direitos Humanos das Nações Unidas adotou em 2011 um conjunto de diretrizes denominadas Princípios Orientadores sobre Empresas e Direitos Humanos ${ }^{41}$. Tais normas foram elaboradas pelo Representante Especial do Secretário-Geral das Nações Unidas, John Ruggie, e elucidam quais condutas devem ser adotadas pelas organizações empresariais para proteger os direitos humanos. Esse guia é considerado um documento de soft law, pois estabelece diretrizes que configuram medidas de prevenção e reparação em situações que violam os referidos direitos ${ }^{42}$.

Márquez ${ }^{43}$ explica que os Princípios Orientadores indicam que há um risco para as empresas e seus dirigentes de responder a um processo criminal por violações aos direitos humanos. O autor menciona como exemplo o princípio de número 7, que aborda a obrigação dos Estados de garantir que as empresas que atuam em áreas de conflito não se envolvam em situações que desrespeitem os direitos humanos. Os Estados devem adotar providências que permitam identificar as pessoas que pratiquem tais atos para responsabilizá-las civil e criminalmente.

Percebe-se que há uma inclinação das organizações internacionais e dos Estados a estender a questão da proteção dos direitos humanos para incluir atividades desenvolvidas por empresas. Na seção seguinte, serão examinadas quais medidas podem ser adotadas em programas de compliance ou cumprimento normativo para evitar graves violações aos direitos humanos, tais como tráfico humano e trabalho escravo.

\footnotetext{
${ }^{41}$ ORGANIZAÇÃO DAS NAÇÕES UNIDAS. Princípios Orientadores sobre Empresas e Direitos Humanos. Disponível em: https://www.socioambiental.org/sites/blog.socioambiental.org/files/nsa/arquivos/conectas_principiosorientadores ruggie_mar20121.pdf.

42 MÁRQUEZ, Daniel Iglesias. La responsabilidad penal de las empresas por graves violaciones de derechos humanos: práctica actual y desafíos futuros. Revista de Direito Internacional, Brasília, v. 15, n. 2, 2018 , p. 132. ${ }^{43}$ Idem.
} 


\section{PROGRAMAS DE CUMPRIMENTO NORMATIVO COMO MECANISMOS DE PREVENÇÃO DE CRIMES TRABALHISTAS}

Há algum tempo a expressão "responsabilidade social da empresa" é mencionada no meio empresarial. Trata-se de um conceito de difícil definição, conforme Bertoncello e Chang Júnior $^{44}$, pois está relacionado a ideias distintas. Enquanto para parte da doutrina esse conceito se relaciona com a ideia de responsabilidade legal, outros podem considerar que se trata da postura ética que os funcionários da organização devem assumir. Existem ainda pessoas que consideram que a responsabilidade social é tudo o que abrange os impactos diretos e aqueles que afetam terceiros.

Nesse último caso, que entende esse conceito como algo que envolve impactos diretos e em relação à terceiros, a responsabilidade social apresentaria várias facetas, tais como: relações de parceria entre clientes e fornecedores, produção com qualidade; satisfação dos usuários, contribuições para o desenvolvimento da comunidade; investimentos em pesquisa tecnológica, conservação do meio ambiente; participação de funcionários nos resultados e nas decisões das empresas; respeito aos direitos dos cidadãos; não discriminação dos gêneros, raças, idades, etnias, religiões, ocupações ou preferências sexuais; investimentos em segurança do trabalho e em desenvolvimento profissional ${ }^{45}$.

Esse conceito mais abrangente de responsabilidade social da empresa é o que melhor se adequa ao contexto atual, ou seja, entende-se que as organizações também devem contribuir para a proteção dos direitos fundamentais. Nessa seção utilizaremos a expressão "direitos humanos", os direitos do indivíduo mencionados em documentos internacionais, sem vinculação a uma ordem constitucional específica.

A noção de responsabilidade social empresarial se desenvolveu para abarcar variados tópicos, segundo Alvaro Cuervo-Cazurra ${ }^{46}$, inerentes a três campos principais: econômico,

\footnotetext{
${ }^{44}$ BERTONCELLO, Silvio Luiz Tadeu; CHANG JÚNIOR, João. A importância da Responsabilidade Social Corporativa como fator de diferenciação. Revista da Faculdade de Comunicação da FAAP, São Paulo, v. 1, n. 17 , p. 70.

45 Ibidem, p. 76.

${ }^{46}$ CUERVO-CAZURRA, Alvaro. The Evolution of Business Groups' Corporate Social Responsibility. Journal of Business Ethics, dez. 2018, vol. 153, p. 1001.
} 
social e ambiental. Os assuntos abordados no âmbito desse conceito são sintetizados como 3Ps: profit, people, planet (benefício, pessoas, planeta). Esses três tópicos focam em medidas de sustentabilidade, que devem ser os principais pontos de investimento na empresa.

Para se adequar a esse conceito de responsabilidade social corporativa, é interessante para a empresa a criação de um programa de conformidade normativa, ou seja, medidas voltadas para proteger e corrigir violações a direitos humanos, de acordo com Mazzuoli e Cunha ${ }^{47}$. A responsabilidade social da empresa, bem como a sustentabilidade das cadeias produtivas, atribuem eficácia às políticas públicas que têm por objetivo concretizar os direitos sociais e combater a corrupção no país, de modo que é necessário incentivar esse modelo empresarial.

Há tratados internacionais que dispõem sobre a responsabilidade social corporativa que devem ser seguidos pelas organizações. Como exemplos mais relevantes de tratados nesse sentido, é possível mencionar: a Declaração Universal de Direitos Humanos, proclamada pela Organização das Nações Unidas (ONU) em 1948 e os Pactos Internacionais sobre Direitos Civis e Políticos e sobre Direitos Econômicos, Sociais e Culturais, firmados em Nova York no ano de 1966.

Os investimentos sociais devem ser voltados ao suporte dos empregados e das comunidades nas quais as empresas desenvolvem suas atividades, bem como em medidas que envolvam a diminuição de riscos que exponham os empregados a situações desfavoráveis e que, por conseguinte, prejudiquem suas reputações.

A exploração trabalhista se apresenta, atualmente, como uma situação que vem se expandindo e se tornando frequente, sobretudo nos países em desenvolvimento e subdesenvolvidos. Dessa forma, é necessário que haja alguma intervenção penal para impedir o crescimento desse fenômeno, o que pode ser feito, conforme Terradillos Basoco ${ }^{48}$, por meio de uma política criminal preventiva, uma condição que compatibiliza as relações laborais com os requisitos de um trabalho em condições dignas.

47 MAZZUOLI, Valério; CUNHA, Matheus Lourenço Rodrigues da. Compliance: de instrumento de sustentabilidade empresarial a mitigador de violações a direitos humanos e fundamentais. Revista Jurídica UNIGRAN. Dourados, 2018, vol. 20, n. 39, p. 29.

${ }^{48}$ BASOCO, Juan María Terradillos. Explotación laboral, trabajo forzoso, esclavitud: ¿Retos político-criminales para el sigloXXI?. In: CRESPO, Eduardo Demetrio; NIETO MARTÍN, Adán. Derecho penal econômico y Derechos Humanos, Valencia: 2018, p. 215-216. 
Mazzuoli $^{49}$ e Cunha mencionam de forma sucinta as normas previstas pela ONU acerca da responsabilidade social das empresas: obrigações gerais sobre o cumprimento e proteção dos direitos humanos; direito à igualdade de oportunidade e tratamento não discriminatório; direito à segurança dos indivíduos; direito dos trabalhadores; respeito à soberania nacional e os direitos humanos; obrigações acerca da proteção do meio ambiente; e implementação de cláusulas gerais sobre à operacionalização e fiscalização por organismos credenciados, assim como análises dos impactos das atividades das empresas.

Faz-se necessário ressaltar que essas diretrizes devem ser concretizadas para promover resultados práticos tanto no cenário empresarial interno quanto no internacional. A questão relativa ao direito dos trabalhadores, especialmente no que tange à vedação de formas de trabalho compulsório, como é possível perceber, trata-se de uma preocupação a nível internacional, que as empresas não podem deixar de considerar no desenvolvimento de suas atividades.

Para cumprir tais orientações que visam prevenir crimes trabalhistas, Terradillhos Basoco $^{50}$ ressalta que as fórmulas legais elaboradas conforme a criminalidade do século XIX podem ser pouco eficazes para combater as violações de direitos humanos que ocorreram a partir do século XX.

Ressalte-se que o problema das relações laborais ilícitas é, antes de ser uma questão que preocupa o Estado e a sociedade em geral, uma violação aos direitos fundamentais de cada um dos trabalhadores vítimas dessas condutas. O descumprimento das normas de direitos humanos nas relações trabalhistas ainda é uma situação recorrente, tendo em vista as crises econômicas enfrentadas por vários países, e essas situações de violações de tais direitos podem, inclusive, se configurar como crimes.

Cumpre salientar que a preocupação em executar tais medidas voltadas a evitar crimes trabalhistas não está limitada somente aos núcleos operacionais da empresa, mas também aos diretores ou membros do conselho fiscal e da administração. Isso demonstra que as organizações empresariais estão tomando as devidas preocupações com a sustentabilidade não apenas por conta do risco de sanções, mas porque a cultura de práticas antiéticas é maléfica

\footnotetext{
${ }^{49}$ MAZZUOLI, Valério; CUNHA, Matheus Lourenço Rodrigues da, op. cit., p. 29.

${ }^{50}$ BASOCO, Juan María Terradillos, op. cit., p. 217-218.
} 
para os negócios e desfavorece a empresa, tornando-a menos competitiva aos olhos dos consumidores de seus produtos ou serviços e do mercado em geral $^{51}$.

Dessa maneira, a implementação de um programa de conformidade normativa que atente para a legislação nacional e internacional a respeito de crimes trabalhistas se faz relevante para a empresa que deseja se manter no mercado a longo prazo. Além dos prejuízos relativos à reputação da empresa perante os consumidores, há a questão de a empresa ter dificuldades no futuro para selecionar funcionários. Afinal, o histórico de envolvimento com casos de trabalho escravo é um fator que desestimula as pessoas a buscarem empregos naquela organização, por receio de que seus direitos fundamentais sejam desrespeitados e mesmo por conta da associação de sua pessoa à uma empresa que emprega trabalhadores em condições que violam os direitos humanos.

É possível também que outras empresas não queiram estabelecer parcerias com uma organização que se vale de tais práticas, justamente para se precaver de sanções futuras e riscos reputacionais. Em suma: nenhuma organização empresarial descomprometida com práticas éticas será bem vista pela sociedade em geral, pois há no senso comum a ideia de que as empresas devem proporcionar boas condições trabalhistas aos seus funcionários, ou seja, devem respeitar seus direitos fundamentais.

Coimbra e Manzi ${ }^{52}$ destacam que o valor da dignidade da pessoa humana está enraizado na consciência coletiva moderna, de modo que se compreende que as relações econômicas devem servir às relações entre indivíduos e não o contrário. Assim, o respeito aos direitos humanos deve permear todas as relações estabelecidas pela organização, não apenas com seus funcionários, mas com todos os entes da sociedade em geral.

Os autores ainda explicam que a ligação entre empresas e direitos humanos apresentase como uma nova área de interesse dentro do campo da cidadania corporativa. Há uma tendência, seguida por algumas organizações, a editar cartas ou códigos de direitos humanos para direcionar a sua atuação ${ }^{53}$. Os mecanismos utilizados para preservar esses direitos podem

\footnotetext{
${ }^{51}$ MAZZUOLI, Valério; CUNHA, Matheus Lourenço Rodrigues da, op. cit., p. 30.

${ }^{52}$ COIMBRA, Marcelo de Aguiar; MANZI, Vanessa Alessi. Manual de Compliance: Preservando a Boa Governança e a Integridade das Organizações. São Paulo: Atlas, 2010, p. 31.

${ }^{53}$ Idem.
} 
ser os mais variados. As empresas devem agir de forma a respeitar os direitos trabalhistas de seus funcionários, proporcionando condições adequadas, saudáveis e seguras de trabalho. Ademais, um pagamento de um salário adequado, que possa satisfazer as necessidades básicas do indivíduo, é uma medida imprescindível para a efetivação dos direitos humanos.

A preocupação de desenvolver as atividades da empresa observando a legislação pertinente pode ser considerada um modelo de realização de negócios. Conforme já mencionado anteriormente, na época atual, as empresas vêm sendo avaliadas pelo mercado não apenas por sua capacidade de gerar lucros, mas por sua reputação. Para Coimbra e Manzi ${ }^{54}$, o compliance atinge todas as áreas de atuação da empresa, tais como seus aspectos nucleares e a forma de executar suas práticas, de modo que pode ser considerado um modelo específico de negócios que tem como sua base a integridade.

O Brasil já tem demonstrado uma inclinação para apoiar cada vez mais tal modelo. O Decreto-lei $\mathrm{n}^{\circ} 9.571^{55}$, de 21 de novembro de 2018, estabelece diretrizes que as empresas devem cumprir para desenvolver suas atividades respeitando os direitos humanos. Tal norma indica as medidas que devem ser adotadas pelas organizações empresariais para atingir esses objetivos.

Dos mecanismos mencionados na referida legislação, destacam-se o monitoramento constante do respeito aos direitos humanos na cadeia de produção empregada pela empresa, conforme o artigo $5^{\circ}$, I. Para Coimbra e Manzi ${ }^{56}$, os riscos são inerentes a todas as organizações e não há uma medida capaz de eliminá-los totalmente. Dessa forma, as atividades das empresas devem ser constantemente monitoradas, de maneira que os riscos sejam minimizados tanto quanto possível e seus impactos sejam minorados. Caso a organização não realize essa fiscalização está adicionando um risco adicional ao seu funcionamento.

Os autores mencionam algumas circunstâncias que configuram situações de fiscalização ${ }^{57}$. Pode ser considerada como exemplo de medida de monitoramento a verificação de novos produtos e serviços para que se adequem à legislação aplicável. Além disso, é

\footnotetext{
${ }^{54}$ Ibidem, p. 18.

55 BRASIL. Decreto no. 9.571, de 21 de novembro de 2018. Estabelece as diretrizes sobre Empresas e Direitos Humanos. Presidência da República. Disponível em: http://www.planalto.gov.br/ccivil_03/_ato20152018/2018/decreto/D9571.htm. Acesso 01 jul. 2019.

${ }^{56}$ COIMBRA, Marcelo de Aguiar; MANZI, Vanessa Alessi, op. cit., p. 92.

${ }^{57}$ Ibidem, p. 93.
} 
necessário realizar o acompanhamento da divulgação das normas externas concernentes às atividades da empresa e, por conseguinte, providenciar o alinhamento das normas internas com as primeiras, por meio de avisos aos setores afetados.

Apesar de ser motivo de controvérsias em algumas classes profissionais, a aprovação de clientes e operações também é considerada uma medida de monitoramento relevante para determinadas empresas ${ }^{58}$. Por meio dessa providência, a organização pode evitar relações com pessoas envolvidas em crimes como lavagem de dinheiro. Essa medida pode ser compreendida como indiretamente protetora dos direitos fundamentais dos trabalhadores da empresa, para que eles não sejam culpabilizados por condutas que não tiveram a intenção de cometer.

$\mathrm{O}$ artigo $5^{\circ}, \mathrm{V}$ menciona que um código de conduta acessível que esteja em conformidade com as normas de direitos humanos deve ser adotado. Tal medida de cumprimento normativo deve ser compreendida em sentido amplo, de forma que não signifique somente uma reunião de normas de comportamento dos funcionários da empresa em um documento específico ${ }^{59}$. Ele deve abranger também normas que versem sobre sustentabilidade, responsabilidade social e ambiental e governança corporativa.

Contudo, é necessário ressaltar que o código de ética não deve ser algo meramente utilizado para que a empresa seja avaliada de forma positiva pelos órgãos reguladores. Ele deve ser acessível, escrito de forma clara para que todos os funcionários consigam entender o sentido das disposições contidas no referido documento ${ }^{60}$. Apenas assim ele poderá ser devidamente aplicado pelas pessoas que trabalham na organização.

Além de apresentarem fácil assimilação, as ações contidas no código de conduta devem ser concretizadas, para viabilizar a manutenção da empresa em padrões de conformidade normativa. A participação de funcionários de setores variados da empresa na elaboração do código também pode ser algo vantajoso para a empresa, pois isso facilita a adaptação de tais trabalhadores às disposições contidas no documento ${ }^{61}$.

\footnotetext{
58 Idem.

${ }^{59}$ Ibidem, p. 84.

${ }^{60}$ Idem, p. 85.

${ }^{61}$ CANDELORO, Ana. Paula.; RIZZO, Maria Balbina Martins de.; PINHO, Vinicius. Compliance 360 ${ }^{\circ}$. São Paulo: Edição do Autor, 2015. p. 58.
} 
O código de conduta deve estabelecer soluções para situações de conflito que possam vir a ocorrer no âmbito da empresa. Em caso de conflito, o setor de compliance da empresa deve ser comunicado para que sejam tomadas as providências necessárias e para que os funcionários recebam as devidas orientações de como proceder na situação de dúvida, conforme elucidam Candeloro, Rizzo e Pinho ${ }^{62}$. Cabe às políticas da empresa, e não ao código de ética, fornecer as diretrizes para conduzir as pessoas que trabalham na organização ${ }^{63}$.

O referido decreto cita ainda que a empresa deve tomar medidas de conscientização e treinamento para que funcionários, colaboradores e parceiros comerciais tomem ciência da política da organização e entendam como devem conduzir suas atuações no desenvolvimento de suas atividades relacionadas à empresa. Coimbra e Manzi destacam que um dos maiores riscos a um programa de conformidade normativa é a falha na comunicação da política e dos procedimentos da empresa aos seus funcionários ${ }^{64}$. A participação de todos colaboradores da empresa em sessões de treinamento deve ser obrigatória e essas devem conscientizar sobre a relevância de se aderir a uma cultura de integridade ${ }^{65}$.

Há, ainda, no artigo 10 do Decreto n 9571 a disposição de que é de responsabilidade da empresa criar mecanismos de denúncia e reclamação que viabilizem diminuir os riscos ou reparar os danos causados, se houver. O canal de comunicação deve ser um mecanismo que não apenas permita denúncias, mas que possibilite que os colaboradores tirem dúvidas e façam sugestões para a manutenção da política da empresa.

As medidas retromencionadas são mecanismos de cumprimento normativo que precisam ser implementadas para que as empresas se adaptem às normas de direitos humanos. Não se trata somente de satisfazer requisitos exigidos pelo Estado, mas assegurar os direitos fundamentais de seus funcionários. Essas providências evitam que bens jurídicos sejam violados em situações que configurem exploração trabalhista ou assédio moral. Ademais, essas diligências minimizam o risco de envolvimento dos funcionários da empresa em condutas criminosas.

\footnotetext{
${ }^{62}$ Ibidem, p. 59.

${ }^{63}$ COIMBRA, Marcelo de Aguiar; MANZI, Vanessa Alessi. Manual de Compliance: Preservando a Boa Governança e a Integridade das Organizações. São Paulo: Atlas, 2010, p. 92.

${ }^{64}$ Ibidem, p. 87.

${ }^{65}$ Ibidem, p. 88.
} 


\section{CONSIDERAÇÕES FINAIS}

Pode-se considerar que a adoção de uma política que preserve os direitos fundamentais de seus funcionários e colaboradores demonstra que a empresa não está preocupada apenas com geração de lucro por meio de suas atividades. Embora já seja ponto pacífico em diversos ordenamentos jurídicos que tais direitos devem ser observados em relações entre entes privados, a disseminação dessa cultura é um importante passo para a evolução do cenário empresarial mundial.

A preservação dos direitos fundamentais dos funcionários deve ser uma medida concretizada para que as empresas conservem uma imagem íntegra no mercado. Os investidores estão cada vez mais preocupados com a reputação das empresas com as quais estão mantendo ou pretendem manter relações comerciais. Além disso, os consumidores dos produtos ou serviços oferecidos pela organização podem vir a deixar de adquiri-los com o intuito de não financiar práticas exploradoras de mão de obra.

Dessa forma, percebe-se que há um reconhecimento crescente entre a maior parte das sociedades, pelo menos no hemisfério ocidental, de que as relações trabalhistas não devem ocorrer sem que os direitos fundamentais das partes envolvidas sejam preservados. É possível considerar tal fato como uma decorrência da disseminação do conceito de dignidade da pessoa humana.

A responsabilidade social da empresa está diretamente relacionada à forma como ela trata seus funcionários. Assim, medidas como canais de denúncia, investigações corporativas internas e averiguação de empresas com as quais mantém parcerias podem ser entendidas como concretizadoras de direitos fundamentais de todos os indivíduos que colaboram no desenvolvimento das atividades da organização empresarial em questão. 


\section{REFERÊNCIAS}

ALEXY, Robert. Teoria dos Direitos Fundamentais: 2. ed. São Paulo: Malheiros Editores, 2011.

AMARAL, Gustavo. Direito, Escassez \& Escolha: Em busca de critérios jurídicos para lidar com a escassez de recursos e as decisões trágicas. Rio de Janeiro: Renovar, 2001.

BASOCO, Juan María Terradillos. Explotación laboral, trabajo forzoso, esclavitud: ¿Retos político-criminales para el sigloXXI?.. In: CRESPO, Eduardo Demetrio; NIETO MARTÍN, Adán. Derecho penal econômico y Derechos Humanos, Valencia: 2018, p. 215-243.

BENEDETTI, Carla Rahal. Criminal Compliance: instrumento de prevenção criminal corporativa e transferência de responsabilidade penal. São Paulo: Quartier Latin, 2014.

BERTONCELlO, Silvio Luiz Tadeu; CHANG JÚNIOR, João. A importância da Responsabilidade Social Corporativa como fator de diferenciação. Revista da Faculdade de Comunicação da FAAP, São Paulo, v. 1, n. 17, p. 70-76. 2007.

BRASIL. Constituição da República Federativa do Brasil. Disponível em: www.planalto.gov.br/cf1988.

BRASIL. Supremo Tribunal Federal. Recurso Extraordinário n.466.343-SP. Recorrente: Banco Bradesco S.A. Recorrido: Luciano Cardoso Santos. Relator: Min.Cezar Peluso. DJe 104. Publicado em 05.06.2009. Disponível em: http://redir.stf.jus.br/paginadorpub/paginador.jsp?docTP=AC\&docID=595444.

BRASIL. Decreto no. 9.571, de 21 de novembro de 2018. Estabelece as diretrizes sobre Empresas e Direitos Humanos. Presidência da República. Disponível em: http://www.planalto.gov.br/ccivil_03/_ato2015-2018/2018/decreto/D9571.htm. Acesso 01 out. 2019.

BRITO, Teresa Quintela de. Relevância dos mecanismos de "Compliance" na responsabilização penal das pessoas coletivas e dos seus dirigentes. Revista de Ciências Jurídico-Criminais, Coimbra, p. 75-91, 2014.

CABETTE, Eduardo Luiz Santos; NAHUR, Marcius Tadeu Maciel. Criminal Compliance e Ética Empresarial. Porto Alegre: Núria Fabris, 2013.

CANDELORO, Ana. Paula.; RIZZO, Maria Balbina Martins de.; PINHO, Vinicius. Compliance 360'. São Paulo: Edição do Autor, 2015.

CARDOSO, Débora Motta. Criminal compliance na perspectiva da lei de lavagem de dinheiro. São Paulo: LiberArs, 2015.

COIMBRA, Marcelo de Aguiar; MANZI, Vanessa Alessi. Manual de Compliance: Preservando a Boa Governança e a Integridade das Organizações. São Paulo: Atlas, 2010. 
DIMOULIS, Dimitri; MARTINS, Leonardo. Teoria Geral dos Direitos Fundamentais: 3. ed. São Paulo: Editora Revista dos Tribunais, 2011.

CUERVO-CAZURRA, Alvaro. The Evolution of Business Groups' Corporate Social Responsibility. Journal of Business Ethics, dez. 2018, vol. 153, p. 997-1016

KUHLEN, Lothar. Cuestiones Fundamentales de Compliance y Derecho Penal. In: KUHLEN, Lothar; MONTIEL, Juan Pablo; GIMENO, Ínigo Ortiz de Urbina. Compliance y Teoría del Derecho Penal. Madrid: Marcial Pons, 2013, p. 51-76.

MÁRQUEZ, Daniel Iglesias. La responsabilidad penal de las empresas por graves violaciones de derechos humanos: práctica actual y desafíos futuros. Revista de Direito Internacional, Brasília, vol. 15, n. 2, 2018, p. 130-149.

MAZZUOLI, Valério; CUNHA, Matheus Lourenço Rodrigues da. Compliance: de instrumento de sustentabilidade empresarial a mitigador de violações a direitos humanos e fundamentais. Revista Jurídica UNIGRAN. Dourados, v. 20, n. 39, p. 13-52. Disponível em: https://www.unigran.br/revista_juridica/ed_anteriores/39/artigos/artigo01.pdf. Acesso em 25 set. 2019.

NIETO MARTÍN, Adán. O Cumprimento Normativo. In: NIETO MARTÍN, Adán; LASCURAIIN SÁNCHEZ, Juan Antonio; GARCÍA DE LA GALANA, Beatriz; FERNANDEZ PÉREZ, Patricia; BLANCO CORDERO, Isidoro. Manual de Cumprimento Normativo e Responsabilidade Penal das Pessoas Jurídicas. Florianópolis: Tirant lo blanch, 2018, p. 2953.

ORGANIZAÇÃO DAS NAÇÕES UNIDAS. Princípios Orientadores sobre Empresas e Direitos Humanos. Disponível em: https://www.socioambiental.org/sites/blog.socioambiental.org/files/nsa/arquivos/conectas_pri ncipiosorientadoresruggie_mar20121.pdf. - Acesso em 20 out. 2019.

PIOVESAN, Flávia. Direitos humanos e o direito constitucional internacional. 11 ed. rev. e atual. São Paulo: Saraiva, 2010.

RAMOS, André de Carvalho. Teoria geral dos direitos humanos na ordem internacional. 2 ed. São Paulo: Saraiva, 2012.

SÁ, Ana Luíza. Compliance Criminal: reflexos de sua adoção pelo particular. In: SAADDINIZ, Eduardo; ADACHI, Pedro Podboi; DOMINGUES, Juliana Oliveira (Org.). Tendências em governança corporativa e compliance. São Paulo: LiberArs, 2016. p. 223229.

SAAD-DINIZ, Eduardo. Novos modelos de responsabilidade empresarial: a agenda do direito penal corporativo. In: SAAD-DINIZ Eduardo; ADACHI, Pedro Podboi; DOMINGUES, Juliana Oliveira (Org.). Tendências em governança corporativa e compliance. São Paulo: LiberArs, 2016. p. 91-98. 
SAAVEDRA, Giovani Agostini. Reflexões iniciais sobre criminal compliance. Boletim IBCCRIM, São Paulo, ano 18, n. 218, p. 11-12, jan. 2011. Disponível em: http://espacocriminologico.blogspot.com.br/2011/01/reflexoes-iniciais-sobre-criminal.html. Acesso em: 22 jun. 2019.

SARCEDO, Leandro. Compliance e responsabilidade penal da pessoa jurídica: construção de um novo modelo de imputação baseado na culpabilidade corporativa. São Paulo: Saraiva, 2016.

SARLET, Ingo Wolfgang. A Eficácia dos Direitos Fundamentais: uma teoria geral dos Direitos Fundamentais na perspectiva constitucional. 11. ed. Porto Alegre: Livraria do Advogado Editora, 2012.

SARMENTO, Daniel. Dignidade da Pessoa Humana: conteúdo, trajetórias e metodologia. Belo Horizonte: Editora Fórum, 2016.

SARMENTO, Daniel. Direitos Fundamentais e Relações Privadas. Rio de Janeiro: Lumen Juris, 2006.

SILVEIRA, Renato de Mello Jorge; SAAD-DINIZ, Eduardo. Compliance, Direito Penal e Lei Anticorrupção. São Paulo: Saraiva, 2015.

WEISS, Carlos. Direitos humanos contemporâneos. 2 ed. 3 tiragem. São Paulo: Malheiros Editores, 2012.

Data de Submissão: 15/12/2019

Data de Aceite: 27/02/2020 